\title{
THE NATIONAL LIBRARY OF KOSOVO “PJETËR BOGDANI” RAPID CONDITION ASSESSMENT AND DOCUMENTATION
}

\author{
R. Eppich ${ }^{\mathrm{a}}$, Bekim Ramku ${ }^{\mathrm{a}}$, Nol Binakaj ${ }^{\mathrm{b}}$ \\ a Universidad Politécnia de Madrid, Spain - rr.eppich@alumnos.upm.es \\ b Kosovo Architectural Foundation, Prishtina, Kosovo - ramku.kaf@gmail.com, binakaj.kaf@gmail.com
}

Commission VI, WG VI/4

KEY WORDS: Kosovo National Library, Documentation, Condition assessment, $20^{\text {th }}$ century architectural conservation

\begin{abstract}
:
The National Library of Kosovo "Pjetër Bogdani” is a symbol of Prishtina, Kosovo and the quest for knowledge. It is simultaneously an icon of modernity and symbol of the past. Unfortunately, it suffered through the Kosovo war and neglect in times of economic difficulty. It was also unfortunately featured in the British newspaper The Telegraph in their travel section: “One of the world's 30 ugliest buildings?” In late 2015 the Kosovo Architectural Foundation, a non-profit dedicated to spirit of creating and preserving unique architecture, became concerned with the reputation and condition of the Library and contacted the Kosovo Ministry of Culture, visited the site and initiated a project to raise awareness and document this modern masterpiece. The Getty Foundation and their Keeping it Modern grant program awarded funding for initial condition assessment, documentation, capacity building and investigations. This paper discusses the project to document and improve the image and awareness of this important structure and set priorities for its future.
\end{abstract}

\section{KOSOVO NATIONAL LIBRARY}

\subsection{Introduction}

The building of the National Library of Kosovo was the culminating expression of our architecture and belief for a brighter future through education. It's construction, interior, materials, landscaping planning and environment demanded that the articulation of space, its compact structure, shapes, light and shade, and elevation, should carry associations of traditional buildings of this region while simultaneously creating a new architectonic form. The motifs of cubes, spheres, and columns represent a contemporary application of the autochthonous architectural inspiration of the people of Kosovo.

Andrija Mutnjakovic, Architect, On the beginning of construction of the Library

Few modern buildings connect the past and present as flawlessly and span multiple cultures as expressively as Kosovo's National Library in Prishtina. Reflecting on the region's diverse heritage and distinct cultural spirit, Croatian architect Andrija Mutnjakovic (b. 1929) sought to create an authentic national architectural expression when he designed the building in 1971. Constructed with in-situ cast concrete, marble floors, and white plastered walls, and topped with 99 translucent acrylic domes, the library is reminiscent of buildings from Byzantium and the Ottoman Empire. Despite its unified historic forms, the structure is unmistakably modern. Mutnjakovic used new materials to evoke ancient architectural tropes, most notably the exterior aluminium lattice-wrapping, which can be interpreted either as a fishnet or a veil pointing to the area's two predominant religions. Although reception of the design was mixed when the library opened in 1982, the building is now regarded as an extraordinary example of late Yugoslav modernism and a beloved space in the community.

While the building's interiors suffered damage during the Kosovo War (1998-1999), its exterior escaped the conflict relatively unharmed. However, over the past several years, the building has begun to show signs of aging, most evidently though water ingress that required ad hoc repairs. Moving forward, a team of conservation specialists will address the lack of knowledge about the building, studying and assessing its performance with the support of a Getty grant. They will analyse every aspect of the building, including consulting with the architect on historic documents and his own personal knowledge of the design. Their research will create a comprehensive record of the building's past and current conditions and result in the preparation of a nomination for the protection of the library at the national level. When completed, the project will serve as a model for modern building documentation in the region and will be shared with the public through an exhibition at the library. The project will also raise awareness for preserving 20th century architecture through a series of workshops for students and young professionals in the field. 


\section{VALUES ASSESSMENT/SIGNIFICANCE}

An important part of the study of any historic place is to understand its values. As part of this project these values were explored. Members of the community, Ministry of Culture and architects were involved. These underlying values included aesthetic, historic, social and scientific, etc. The various aspects that were investigated included form and design, materials and substance, use function, location and setting and spirit and feeling. These were placed into the Nara Grid model based upon Koen van Balen to generate a platform for discussion and draft a statement of significance.

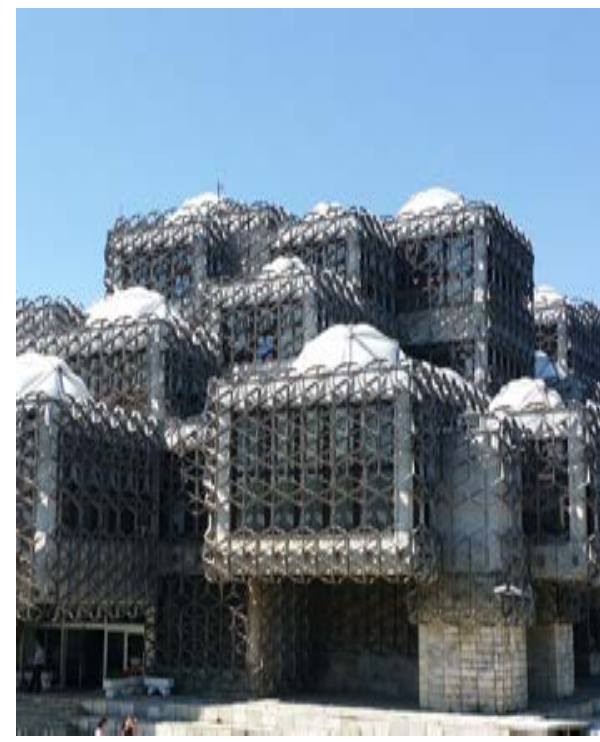

Figure 1 -Exterior of the Kosovo National Library

\subsection{Significance}

The National Library of Kosovo "Pjetër Bogdani” (Biblioteka Kombëtare e Kosovës) is significant for is numerous underlying and overlapping values - to many different communities. It is important to the history of the people of Kosovo as one of the major repositories of knowledge and as a center of learning for multiple generations. It is one of the largest resources of publications in the Albanian language and also shelters historic materials from four periods: the Ottoman, Yugoslav and independent Kosovo periods. Its location in the center of the university campus as well as the center of Prishtina along with its open spaces has given it high social values as a gathering place for the people of Kosovo. Many protests and demonstrations have begun here and it will continue to serve this purpose. It also has social value for individuals or small groups as a meeting point to study or visit the city. The library has a number of historic links given its architectural forms of cubes and domes to both Byzantine and Islamic religious buildings but is a reinterpretation of these forms in modern materials and building techniques. Its solid well-built construction following the idea gesamtkunstwerk or integral design serves as an example of the level of complete design and workmanship possible. The finishes, furnishings, materials and details were thought of as a work of ideal art that is comprehensive in all its elements. This integrity and authenticity are largely intact. This is an important value today given the often inadequate construction methods employed in contemporary buildings.

\subsection{Conservation Philosophy}

Because the Kosovo National Library is an important structure the following Conservation Philosophy was drafted to serve as a guide for its conservation. The Conservation Philosophy and Intervention Principles are written to ensure a professional, international standard for conservation. They will guide future work to conserve the aesthetics, values and historic importance of the monument. They have been drafted to align with international standards of conservation but adapted for the local context.

RESPECT FOR VALUES - These have been studied and will be widely disseminated. One such value is the integrity including finishes and furnishings. Therefore it is important to only touch the library as lightly as possible to preserve the original fabric, authenticity and values. The proper texture, colour and appearance of any patches on the walls, recovery of lighting fixtures and retention of original finishes. This includes reinstallation and conservation of original furnishings.

MINIMUAL INTERVENTION - Only undertake repairs where absolutely necessary for both short and long term stability, moisture protection and visitor safety. Any elements that require replacement must be identified and the causes of deterioration must be studied and understood and addressed before replacement. Maintain reversibility in any intervention when possible and reverse existing inappropriate interventions.

COMPATIBLE MATERIALS - only compatible materials using the same or similar design motif, colour and properties should be used.

TESTING - Test all original materials to thoroughly understand their properties and attributes in order to understand what kind of new materials should be used. Test all new materials and any proposed treatments.

DISCERNIBLE INTERVENTION - all interventions will be slightly discernible form the original materials. This will be marked and documented in a subtle manner.

INTERNATIONAL STANDARDS - all work will conform to all international conservation practices and charters. These are listed in the Bibliography.

MAINTAIN USE - iconic buildings such as the library that are used and known are protected. Therefore unused or underused spaces should be adapted and made available for use. This includes upgrade facilities including handicapped access and signage.

SUSTAINABILITY - Prepare for longer term conservation project including manual for maintenance, list of priority items, protection of fragile area, etc. Control the water on and around the roof, basement and site, improve drainage. Remove harmful vegetation on the plaza and and site particularly around 
drainage. Prevent mechanical damage to remaining elements. Maintenance plan. Write a maintenance and visitation plan.

KNOWLEDGE - Create records and documentation that can be easily followed and serve as a record of all works. This includes locating historic documents and the creation of a bibliography. All work will be communicated and shared with all stakeholders.
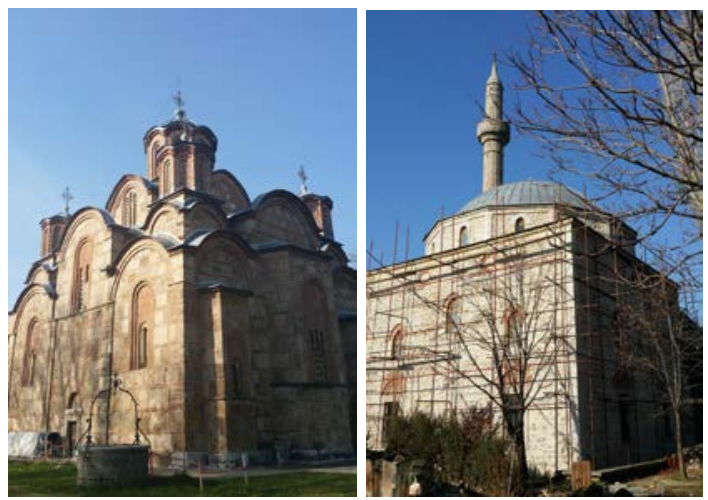

Figure 2 - Historic influences of the Gračanica Monastery and the Ibrahim Lutfiu Mosque in Kosovo.

\section{CONDITION ASSESSMENT DOCUMENTATION}

One of the first steps was to collect all historic drawings and images of the building. The Kosovo Architectural Foundation visited the architect Andrija Mutnjakovic in Zagreb and obtained his drawings as well as videotaping an interview with him. This proved to be very valuable in the initial understanding of his influences as well as issues that arose during construction.

The rapid condition assessment was the second step in a much larger more comprehensive project. The goal of this assessment was to quickly identify areas that required further more in-depth study. The second goal was to conduct a workshop and introduce young architects to the building, its values and condition assessment. The final goal was to begin to communicate with directors and decision makers about the condition of the library. Funding cycles are usually quite long and the team felt it necessary to be prepared should there be questions concerning intervention budgets.

This assessment was possible using two different methods: either by building system such as moisture protection or by physical spaces. The team chose to describe the condition using both because division by physical spaces allowed for a more efficient workshop and use of the participants teams while by systems it is easier to identify and communicate systemic problems. Also this helped the young architects the possibility of seeing all systems within a single space. It will also help decision makers and funders focus on particular spaces such as the reading rooms or offices.

The team drafted a form that would unify efforts in documenting the building and assessing its condition. The form listed spaces, building systems such as water protection and heating, ventilation and air conditioning. A particular focus was on life safety followed by water protection. It was emphasised how this form was connected to the values explored earlier. Special emphasis was placed upon disabled access from the parking lot to a majority of the spaces, the original finishes and furnishings as well as items that may be at risk in the future. One additional aspect of this form is that it could be used in the future to monitor the building by the maintenance workers. These forms were tested in various portions of the building before deciding upon a standard form that would work for the whole. The teams then dispersed to investigate all aspects of the building. In addition to the form extensive photography was undertaken following a strict methodology that included the context, space, photo plan and details of the issued investigated. These were then referenced into the form for retrieval later. After several intense days of investigation the forms were brought together to create a comprehensive condition assessment report that was then translated and presented to the Ministry of Culture.

\begin{tabular}{|l|l|l|l|l|}
\hline 1 & & \\
\hline 3 & Conservation Plan for the Kosovo National Library \\
\hline 4 & Rapid Condition Assessment & \\
\hline 5 & & floor (2nd) & \\
\hline 6 & ROOM NUMBER & 7 & \\
\hline 7 & NAME & & \\
\hline 8 & DATE & & \\
\hline 9 & & & \\
\hline 10 & Life safety & & \\
\hline 11 & egress (exit) & & \\
\hline 12 & hand rails & & \\
\hline 13 & places to fall & & \\
\hline 14 & fire extinguishers & & \\
\hline 15 & & & \\
\hline 16 & Structure & & \\
\hline 17 & cracks & & \\
\hline 18 & insects & & \\
\hline 19 & rot & & \\
\hline 20 & & & \\
\hline 21 & Moisture & & \\
\hline 22 & condensation & & \\
\hline 23 & & & \\
\hline 24 & Finishes & & \\
\hline 25 & Asbestos & authenticity & & \\
\hline & & & \\
\hline
\end{tabular}

Figure 3 - Sample documentation form that was used for building condition assessment to identify issues

The documentation revealed that overall the National Library of Kosovo is in good condition. There are no major structural issues such as deformation, differential settlement or cracking. There are minor areas at the bottom of the cantilevers where the reinforcing bars are exposed and these require treatment.

However there are more serious issues that must be addressed. This includes water infiltration from the roof. The flat built-up roof membrane, flashings, copings, scuppers and drains are all failing. There have been remedial actions over the years but it is time for the roof to undergo a redesign and new roof to ensure the building will last for another 40 years. The roof must 
undergo a redesign that will add additional insulation, increase the drainage slope, provide better control of water from the drain scuppers and provide backup roof drains should there be a blockage.

There are also serious issues with water infiltration into the basement and cellars of the building. From the reports that emerged during the archival research this has been a problem since the beginning. While excavation of the entire perimeter of the basement is cost prohibitive there may be other solutions such as a series of shallow wells or channels to dewater the site. Such well can also be installed within the building inside the vertical ventilation shafts. This requires testing and documentation but could be less invasive and more cost effective than new water proofing of the basement walls.

In addition the façade must be addressed. This includes cleaning and repointing of the stone cladding, cleaning the exposed structural members and the aluminum grid. The original wood windows and doors must all be cleaned, sanded, sealed, primed and painted. This will ensure that they remain with the building.

Illumination is also a major concern. Light levels are inadequate for study in the reading rooms. These investigations recorded readings of below 20 lux at night in the reading rooms while the minimum is between 250 and 500 lux. In addition the light levels in other areas of circulation such as the main stair are also insufficient. The light fixtures must be preserved as they are an integral part of the design of the library. These can be preserved and upgraded with the use of new technologies such as LED and smart control systems. This will also significantly reduce energy costs currently estimated at 3000 euros per month.

Furniture, finishes and ornamentation is also a serious concern. These elements are important as they were designed specifically for the library. They are at risk because they wear faster and must be replaced. Furniture is also easy to replace and there are many instances of new inappropriate furnishings.

The toilets require upgrades and replacement of water closets, faucets and plumbing. This should be done keeping as much as possible of the original fixtures and finishes. One or or toilets must be converted for disabled access.

All of these proposed interventions must be thought out and prioritized with a search for available funds to begin immediately. What has been discovered and proposed in this report are expensive interventions, but less expensive compared to upcoming further damages should they not be addressed.

Disabled access into the library is also an important consideration. This includes the parking, enforcement of the parking and a path including a ramp into the building.

In conclusion, the library is in good condition but the above issues must be addressed to ensure conservation of this important monument.

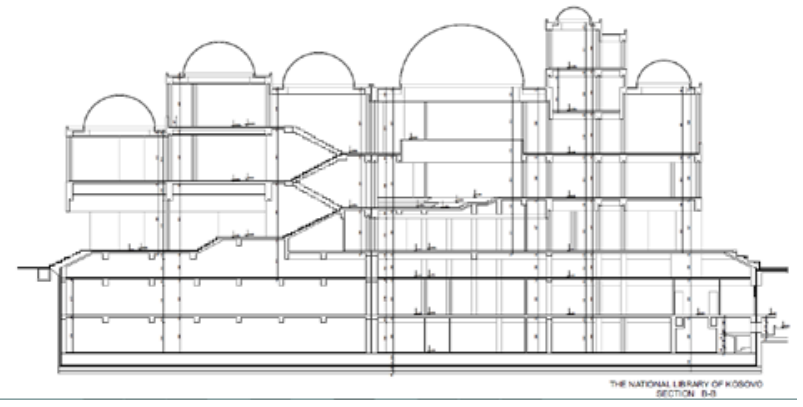

Figure 4 - Section through the library

\section{CONCLUSIONS}

The National Library of Kosovo "Pjetër Bogdani” (Biblioteka Kombëtare e Kosovës) is significant for is numerous underlying and overlapping values. It is at the center of the University, Pristina and Kosovo for knowledge, research and social life. It represents the historic architectural forms of the region in new materials and with new ideas. It also represents an ideal of integrated architectural design that included finishes, furniture and artwork. It is a well-used and functioning building necessary for the social and educational life of the community. It is also a well-respected building and citizens generally take pride in such a unique structure. Knowledge of this significance must be passed on to future generations. Therefore it must be conserved along with all its individual elements. While this project is only the first step in safeguarding this monument it is an important one. The team's activities have already attracted the attention of community leaders, users of the library and university students - an important aspect necessary for the preservation of often under loved modern architecture.

The methodology that was used to document and explore the values as well as the physical condition of the structure proved robust and detailed. The young architects involved in the process as well as the maintenance workers at the Library discovered many items at risk and this allowed for a comprehensive picture to be formed of the condition.

These efforts will help ensure that the National Library of Kosovo is respected, maintained and conserved well into the future.

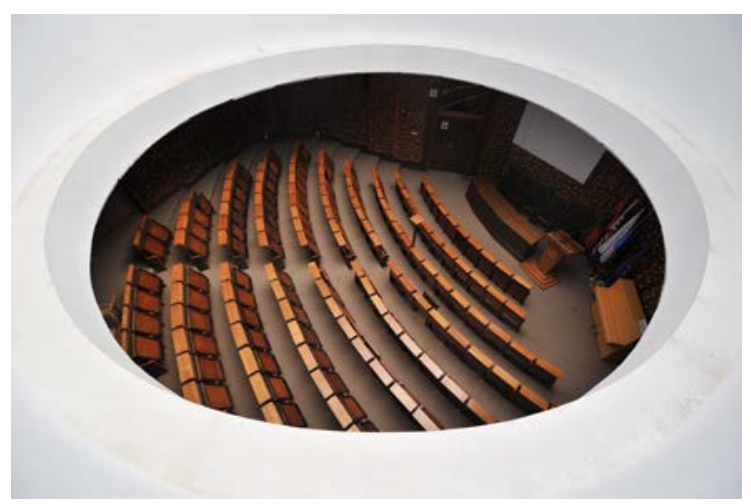

Figure 5 - The main auditorium from above 
Modern architecture is one of the defining artistic forms of the 20th century. Set free from traditional structural requirements, architects and engineers used experimental materials and novel construction techniques to create innovative forms and advance new philosophical approaches to architecture. Today this modern architectural heritage is at considerable risk. The cutting-edge building materials and structural systems that define the modern movement were often untested and have not always performed well over time. Heritage professionals do not always have enough scientific data on the nature and behavior of these materials and systems to develop the necessary protocols for conservation treatment. To address these challenges, the Getty Foundation developed Keeping It Modern, an international grant initiative that continues our deep commitment to architectural conservation with a focus on important buildings of the twentieth century (Getty Foundation).

\section{ACKNOWLEDGEMENTS}

The Kosovo Architectural Foundation team would like to thank The Getty Foundation for providing the financial support and guidance necessary to conduct this project. Through their program of Keeping it Modern this project was possible. It comes at a critical time for the health of the National Library as there are numerous systems such as the roof, windows, moisture protection and plumbing that are nearing failure. The team must thank the Kosovo Ministry of Culture, Youth and Sports for their unwavering support and cooperation. We would also like to thank the managers, librarians and caretakers of the library. In particular Dr. Fazli Gajralku, Director of the Library for his cooperation and welcoming the team to every corner of the library. Special thanks must go to the caretakers of the Library, Pontor Tknikë; Hizri Bekolli, environmental technician; Remzi Demolli, electrician and Valdet Hoti, media technician. It was evident throughout our investigations they take great pride in the library. Without their daily efforts over the past 30 years the building would have suffered. The entire staff assisted us in our efforts to understand the functioning of the building, users, values and condition from the roof to the sub-basement.

\section{REFERENCES}

Abele, Deborah Edge, and Grady Gammage Jr. 2000. The shifting signposts of significance. In Preserving the Recent Past 2. ed. Deborah Slaton and William G. Foulks. Washington, D.C.: Historic Preservation Education Foundation.

Australia ICOMOS. 2000. The Burra Charter: The Australia ICOMOS Charter for Places of Cultural Significance 1999: With Associated Guidelines and Code on the Ethics of CoExistence. Burwood, Vic.: Australia ICOMOS.

Banham, Reyner. 1962. Guide to Modern Architecture. Princeton, N.J.: Van Nostrand. 1966. The New Brutalism: Ethic or Aesthetic? Documents of Modern Architecture 5. New York: Reinhold Publishing.
Defreese, M. 2009. Kosovo: Cultural Heritage in Conflict Journal of Conflict Archaeology Vol. 5 , Iss. 1,2009

Getty Conservation Institute, ICOMOS 2011. Developing an Historic Thematic Framework to Assess the Significance of Twentieth-Century Cultural Heritage: An Initiative of the ICOMOS International Scientific Committee on TwentithCentury Heritage, Experts Meeting.

Getty Foundation 2017 Keeping it Modern grant initiative.

ICOMOS 1994. The Nara Document on Authenticity

Lo, Chung-man, T. 2012. The first step to safeguard our modern architectural heritage: identification, registration and documentation, University of Hong Kong

Song Gang, Yang Chang-Ming, Hao Chen and Ran Yan-Ping, 2014. Weights of the Value Assessment Indicators in Integrated Conservation of Modern Architectural Heritage. Journal of Applied Sciences, 14: 580-585.

Silva, P. Zancheti, S. 2014. Attributes of Modern Architecture and Conservation Action, Centro de Estudos, Avançados da Conservaçoa Integrada, Vol. 59

The Telegraph, One of the World's ugliest buildings? http://www.telegraph.co.uk/travel/lists/ugliest-buildings-in-theworld/national-library-pristina/

UNESCO 2003. Identification and Documentation of Modern Heritage, World Heritage papers 5

Van Balen. K. 2008. The Nara Grid: An Evaluation Scheme Based on the Nara Document on Authenticity, APT Bulletin, Vol 39, No 2/3 pp. 39-45

\section{APPENDIX}

The Kosovo Architectural Foundation is a non-profit, nongovernmental organization based in Prishtina, Kosovo dedicated to spirit of creating and preserving unique architecture. KAF initiated and directs the well-known Prishtina Architectural Week; an annual event attended by thousands of individuals and world famous architects.

http://www.prishtinaarchitectureweek.com/

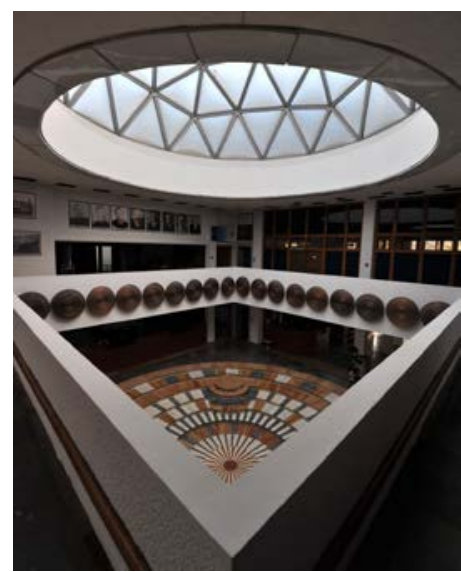

Figure 6 - The main atrium 